\title{
Minimally invasive transforaminal lumber interbody fusion and degenerative lumbar spine disease
}

\author{
Antonio Tsahtsarlis · Martin Wood
}

Received: 21 October 2011/Revised: 28 April 2012/ Accepted: 10 May 2012/Published online: 13 June 2012

(C) Springer-Verlag 2012

\begin{abstract}
Objective The purpose of this study was to assess the clinical and radiological outcomes of minimally invasive transforaminal lumbar interbody fusion (MI-TLIF) surgery for degenerative lumbar spine disease.

Methods A prospective analysis of 34 consecutive patients who underwent a MI-TLIF using image guidance between July 2008 and November 2010. The patient group comprised 19 males and 15 females (mean age 56), 23 of whom had undergone additional reduction of spondylolisthesis. All patients underwent post-operative CT imaging to assess pedicle screw, cage placement and fusion at 6 months. Oswestry Disability Index (ODI) scores were recorded pre-operatively and at 6-month follow up.

Results 33/34 (97.1\%) patients showed evidence of fusion at 6 months with a mean improvement of 27 on ODI scores. The mean length of hospital stay was 4 days. The mean operative time was $173 \mathrm{~min}$.

Complications observed 1/34 (2.9\%) suffered a pulmonary embolism and 1/34 (2.9\%) patients developed transient nerve root pain post-operatively. There were no occurrences of infection and no post-operative CSF leaks. Conclusion MI-TLIF offers patients a safe and effective surgical treatment option to treat degenerative lumbar spine disease.
\end{abstract}

\footnotetext{
A. Tsahtsarlis $(\bowtie) \cdot$ M. Wood

Brisbane Clinical Neuroscience Centre, The Mater Private

Hospital Brisbane, Brisbane, QLD, Australia

e-mail: atsah@hotmail.com

M. Wood

The Mater Neuroscience Centre, Suite 5.02 Mater Private Clinic, 550 Stanley Street, South Brisbane, QLD 4101, Australia

e-mail: mwood@mc.mater.org.au
}

Keywords Transforaminal lumbar interbody fusion . Minimally invasive spine surgery

\section{Introduction}

Advances in lumbar fusion techniques over the years have concentrated on reducing soft tissue injury and neural retraction while maintaining the ability to achieve neural decompression and interbody fusion. The original posterior lumbar interbody fusion (PLIF) was initially introduced by Cloward in 1940 and, with a number of revisions to the technique, remains a widely used technique today [1]. The advantages include the ability to access the majority of the disc space as well as the nerve roots bilaterally and the ability to visualize the anatomy. However, the soft tissue disruption and neural retraction required are significant and may contribute to post-operative discomfort and long-term disability in some patients. In 1982, Harms and Rolinger developed the transforaminal lumbar interbody fusion (TLIF) that, due to the lateral approach to the disc space, reduced the amount of thecal sac and nerve root retraction required [2]. Furthermore, given the unilateral approach, the contralateral interlaminar surface is preserved. Finally, the approach also facilitated the avoidance of epidural scar tissue encountered in revision surgery where a midline decompression had previously been performed. A modified version of the TLIF using unilateral pedicle screws and a translaminar screw has been shown to be an effective option for single level fusions [3]. The indications for TLIF include isthmic and degenerative spondylolisthesis, lumbar facet syndrome and lumbar spinal stenosis with painful degenerative changes or disc related syndromes [4]. Unfortunately, the need for paraspinal muscle dissection and retraction remains a drawback that can lead to muscle 
denervation and atrophy and consequently persistent low back pain [5-8]. In addition, the post-operative pain and disability associated with an open approach led to the development of the minimally invasive TLIF (MI-TLIF). This was first introduced by Foley et al. [9] in 2002 with the aim of reducing tissue damage associated with the exposure and approach while maintaining the ability to achieve neural decompression and adequate interbody fusion. The resultant reported advantages of decreased intraoperative blood loss, decreased post-operative analgesic requirements, early post-operative ambulation and decreased length of hospital stay have made the MI-TLIF an attractive option when treating degenerative lumbar spine disease. However, the procedure is technically quite different from a standard open approach and there are important implications with regard to the surgical learning curve. The purpose of this study is to report our results of MI-TLIF in patients with degenerative lumbar spine disease.

\section{Methods}

\section{Patient population}

Thirty-four consecutive patients with radiological findings consistent with degenerative lumbar spinal disease in the setting of lumbar radiculopathy or claudication underwent instrumented MI-TLIF with computer-assisted image guidance between July 2008 and November 2010. All patients underwent single or two-level procedures and the minimum follow-up period was 6 months. Patient data were recorded prospectively in a clinical database. Assessment of clinical outcome was by Oswestry Disability Index (ODI) scores recorded by the patient before, and at 6 months after, their surgery. Assessment of bony fusion was performed with multiplanar CT scanning at 6 months from the time of surgery. The degree of fusion observed was assessed according to a previously reported protocol [10, 11]. Post-operative complications were also recorded. In particular, the following critical events were specifically sought in all patients: pedicle screw misplacement or interbody cage malposition, as assessed by post-operative CT; new neurological deficit or pain; postoperative CSF leak; post-operative superficial or deep infection; thromboembolic complications; unplanned return to surgery within 30 days and further lumbar surgery within 6 months.

\section{Operative technique}

In all patients a computer-assisted, image-guided technique with stimulus-evoked EMG monitoring of nerve roots was used. Following administration of anaesthesia, muscle relaxants were omitted. Intramuscular needle electrodes were placed into the lower limb muscles that corresponded to the nerve root myotomes at the levels to be instrumented. A reference electrode was placed into the external oblique muscle at the patient's flank, and a grounding return electrode placed on the buttock. Standard mechanical venous thromboembolism precautions (compression stockings and sequential pneumatic compressive devices) were applied to the lower limbs. The electrodes were connected to a monitoring computer (Neural Integrity Monitor (NIM), Medtronic, Memphis, TN). After placing the patient in the prone position, the image guidance system (IGS-Stealth Station, Medtronic, Louisville, CO) reference array was placed percutaneously into the posterior iliac crest and radiographic images obtained on which to base subsequent surgical navigation. In all patients an intra-operative 3D fluoroscopic system (O-arm-Medtronic, Louisville, CO) was used to acquire on-table images. These images were then used to guide placement of the implants with reference to the IGS, without further requirement for intra-operative imaging until the conclusion of the surgery.

\section{Implant placement technique}

By placing a 'virtual' extension on the surgical probe of the navigation system, the correct entry point and trajectory of each pedicle screw were planned so as to place the entry of the pedicle screw at the junction of the transverse process and the facet complex, avoiding the articular surface of the facet joint. A small skin incision was then made at the point corresponding to this trajectory. Using an insulated pedicle access needle that was visible to the IGS and connected to the EMG monitoring system (NIM) at a stimulus of $5 \mathrm{~mA}$, the pedicle was cannulated. If an audible alert signal was produced by the NIM system during pedicle cannulation, the trajectory of the pedicle access needle was modified, using the IGS as a further guide, until no EMG signal was detected. The pedicle access needle was then cannulated with a K-wire and the needle withdrawn. Serial dilators were placed over the K-wire to create a muscular tunnel to the pedicle screw entry point. The pedicle tap and subsequently the pedicle screw were then placed. All pedicles were cannulated prior to performing the interbody fusion, as the distraction of the disc space at this phase of the procedure may have rendered the navigation system inaccurate and make subsequent pedicle cannulation potentially unsafe. It is difficult to perform the TLIF procedure if the pedicle screws with their extenders are in place on the same side as that from which the TLIF is to be performed. For TLIF, we therefore inserted the pedicle screws on the contralateral side, but on the ipsilateral side we cannulated the pedicle with the pedicle access needle sleeves only and 
did not insert the ipsilateral screws until the interbody cage was inserted. This allowed the unimpeded insertion of muscular dilators and an unobstructed view down the operating tube. The decompression and interbody fusion were performed via a $20 \mathrm{~mm}$ cylindrical operating tube (Metrx, Medtronic, Memphis, TN) with an operating microscope, following a technique previously described in detail by Park and Foley [12]. The substantial difference in our series was that the IGS rather than real-time fluoroscopy were used to guide the placement of the operating tube onto the facet joint. Intra-discal distraction of the operated level was achieved with lordotic disc space spreaders (R90, Medtronic, Memphis, TN) and then maintained by insertion and fixation of a percutaneous rod through the pedicle screws on the side contralateral to the TLIF (Sextant, Medtronic, Memphis, TN). This facilitated endplate preparation and insertion of the interbody cage with the disc space distracted. Once the interbody fusion was completed and all screws inserted, the screws were compressed over the interbody cage to provide a degree of segmental lordosis and compression across the cage. The fusion substrate was autologous bone from local facet and/ or lamina harvest, mixed with $1.4 \mathrm{mg}$ recombinant human bone morphogenic protein (rhBMP-2 (Infuse), Medtronic) contained within a PEEK interbody cage device (Capstone, Medtronic, Memphis, CO). In all patients, restoration of anatomical alignment (i.e. reduction) was attempted, with preservation of lordosis. The degree of reduction of the spondylolisthesis and bony fusion was assessed in all patients on post-operative CT scans at 6 months. The degree of fusion was graded based on a previously published grading system [10, 11].

\section{Results}

From July 2008 to November 2010, 34 patients underwent MI-TLIF. Patient demographics and procedural details are listed in Table 1.

\section{Oswestry disability index (ODI) scores}

The pre-operative mean ODI score was 47.8 (range 12-76) and the post-operative mean score 21.1 (range 0-62). The mean change in ODI score was an improvement of 26.7 points (range 10-76).

\section{Spondylolisthesis}

Of the 23 patients with a spondylolisthesis, complete reduction was achieved in 16 patients and partial reduction in 7 patients.
Table 1 Patient demographics and surgical details

\begin{tabular}{|c|c|}
\hline Variable & Outcome \\
\hline Number of patients & 34 \\
\hline Age range & $21-83$, mean 56 years \\
\hline \multicolumn{2}{|l|}{ Sex } \\
\hline Male & $19(56 \%)$ \\
\hline Female & $15(44 \%)$ \\
\hline \multicolumn{2}{|l|}{ Indication } \\
\hline $\begin{array}{l}\text { Spondylolisthesis with radiculopathy/ } \\
\text { canal stenosis }\end{array}$ & 23 \\
\hline Radiculopathy without spondylolisthesis & 11 \\
\hline \multicolumn{2}{|l|}{ Level of fusion } \\
\hline $\mathrm{L} 3 / 4$ & 1 \\
\hline $\mathrm{L} 4 / 5$ & 12 \\
\hline $\mathrm{L} 5 / \mathrm{S} 1$ & 14 \\
\hline L3-5 & 1 \\
\hline L4-S1 & 6 \\
\hline \multicolumn{2}{|l|}{ ODI } \\
\hline Pre op mean & 48 (range 12-76) \\
\hline Post op mean & 21 (range 0-62) \\
\hline Change mean & 27 (range 10-76) \\
\hline \multicolumn{2}{|l|}{ Patient outcome } \\
\hline Improved & 30 \\
\hline Worsened & 3 \\
\hline Unchanged & 1 \\
\hline Workers compensation cases & 9 \\
\hline Improved & 7 \\
\hline Worsened & 1 \\
\hline Unchanged & 1 \\
\hline \multicolumn{2}{|l|}{ Fusion rate at 6 months } \\
\hline Grade I & $25(73.5 \%)$ \\
\hline Grade II & $8(23.5 \%)$ \\
\hline Grade III & $1(2.9 \%)$ \\
\hline \multicolumn{2}{|l|}{ Length of stay (days) } \\
\hline Mean & 4 \\
\hline Median & 3 \\
\hline Range & $2-11$ \\
\hline Operative time (min) & 173 (100-287) \\
\hline
\end{tabular}

Length of hospital stay

The mean length of stay in hospital after surgery was 3.94 (range 2-11, median stay 3 days). The mean length of operation was $173 \mathrm{~min}$.

Bony fusion

Follow-up CT conducted between 6 and 7 months showed evidence of bony fusion in 33/34 (97\%) of patients. This 
was deemed complete in 25 patients with bridging bone and trabecular remodelling, presence of bridging bone but incomplete fusion in eight, and lack of fusion with evidence of endplate osteolysis in one further patient.

\section{Complications}

Post operative complications included two malpositioned screws (one lateral pedicle breach, and one superior pedicle breach), both of which were detected on the end-of-case $\mathrm{O}$-arm images and revised prior to waking the patient. One patient suffered a pulmonary embolus after returning home (without adverse consequence) and one patient developed a new neurological symptom - transient unilateral L5 nerve root pain related to reduction of a grade two spondylolisthesis.

\section{Discussion}

The transforaminal lumbar interbody fusion was introduced by Harms and Rolinger [2]. Its advantages over the posterior lumbar interbody fusion is that it requires a unilateral approach to the disc space, less neural retraction is required to access the disc space and the lateral angle of approach to the disc space enables the surgeon to avoid midline scar tissue in revision surgery. It has been shown to result in shorter surgical times, reduced neural injury and improved overall outcomes [13]. The TLIF has also been compared to anterior-posterior fusion techniques with comparable clinical and radiological outcomes and reduced intraoperative complications [14]. The application of minimally invasive surgical techniques to the TLIF was first described by Foley in 2002 [9]. Several studies have since compared open and MI-TLIF with regards to blood loss, operative time, complication rates, fusion rates, clinical outcome and length of hospital stay. In 2005, Schwender and colleagues [15] reported their results on 49 patients with degenerative disc disease, spondylolisthesis or fracture treated with MITLIF and found improved ODI from a mean of 46 preoperative to 14 post-operatively and a $100 \%$ fusion rate. In 2009, Schizas [16] prospectively compared patients undergoing MI-TLIF and open TLIF and found statistically significant reductions in blood loss, length of stay but differences in ODI scores, operative time and postoperative analgesic requirements. Peng et al. [17] found decreased intra operative blood loss in patients undergoing MI-TLIF and lower complications (6.9 vs $13.8 \%$ ) than in a group of patients undergoing open procedures. Villavicencio and colleagues [18] compared MI-TLIF and open TLIF and found no significant difference in clinical outcomes, operative time or complications in patients with degenerative lumbar disease. Shunwu et al. [19] compared patients undergoing single level TLIF for lumbar degenerative disc disease and spondylolisthesis and found statistically significant reductions in blood loss, time to ambulation, length of hospital stay, and improvement in
Fig. 1 Classification based on post-operative CT imaging

\begin{tabular}{|l|l|l|}
\hline & \multicolumn{1}{|c|}{ Coronal } & Sagittal \\
\hline $\begin{array}{l}\text { Grade I - complete fusion: } \\
\text { Trabecular bone was seen to } \\
\text { bridge the disc space, with } \\
\text { accompanying remodelling of the } \\
\text { cortical end plates }\end{array}$ & & \\
\hline $\begin{array}{l}\text { Grade II - partial fusion: } \\
\text { Trabecular bone seen extending } \\
\text { from the end plate into the disc } \\
\text { space, but forming an incomplete } \\
\text { bridge }\end{array}$ & & \\
\hline $\begin{array}{l}\text { Grade III - no fusion: } \\
\text { No evidence of trabecular bone } \\
\text { formation extending from the } \\
\text { endplates }\end{array}$ & & \\
\hline
\end{tabular}


ODI scores, but significantly longer operative times in the MI-TLIF group. Wang et al. [20] compared MI-TLIF and open TLIF in patients previously treated with discectomy or decompression and found similar operative times, clinical and radiological outcomes but less blood loss and postoperative back pain. Multiple other previous studies have commented on length of inpatient hospital stay of MI-TLIF with a range from 3 to 10.6 days [16-18, 21-24]. Also, mean length of operation has also been previously compared to open procedures with a range from 139 to $300 \mathrm{~min}$ for MI-TLIF [16, 18-24].

In our study, we assessed the results of MI-TLIF in 34 consecutive patients with degenerative disc disease or spondylolisthesis. The mean post-operative ODI score was 21 with a mean improvement of 27 points. With regard to fusion, at 12 months only one patient failed to achieve fusion, which results in a fusion rate of $97 \%$. This is comparable to the results of a recent meta-analysis on previous studies that reported fusion rates of $90.9 \%$ with open procedures compared to $94.8 \%$ for the minimally invasive procedures [25]. This figure is encouraging as one of the potential disadvantages of MI-TLIF is the smaller area available for application of graft (i.e interbody space alone) than in an open procedure, where there is a posterolateral graft bed which can be used in addition to the interbody space (Fig. 1).

The average length of hospital stay for our study was 4 days with a range of $2-11$, which is similar to previous studies' findings. Finally, the mean length of operation in our study was $173 \mathrm{~min}$. The operative time recorded includes time for the percutaneous insertion of the image guidance system and the initial and final on-table image acquisition with the $\mathrm{O}$-arm. This finding may help to alleviate concerns regarding the extension of operating time that may exist with the use of neuronavigation.

\section{Conclusion}

Our results further support MI-TLIF as a safe and effective treatment option of lumbar degenerative disc disease. It produces measurable clinical benefit that is comparable to data from previous studies of open lumbar fusion, results in a short hospital stay and with good rates of solid bony fusion.

\section{Conflict of interest None.}

\section{References}

1. Cloward RB (1953) The treatment of ruptured lumbar intervertebral discs by vertebral body fusion. I: indications, operative technique, after care. J Neurosurg 10:154-168
2. Harms J, Rolinger H (1982) A one-stage procedure in operative treatment of spondylolisthesis: dorsal traction-reposition and anterior fusion [in german]. Z Orthop Ihre Grenzgeb 120:343347

3. Sethi A, Lee S, Vaidya R (2009) Transforaminal lumbar interbody fusion using unilateral pedicle screws and a translaminar screw. Eur Spine J 18(3):430-434

4. Grob D (2009) Surgery for degenerative lumbar disease: transforaminal lumbar interbody fusion. Eur Spine J 18(12):19911992

5. Gejo R, Matsui H, Kawaguchi Y et al (1999) Serial changes in trunk muscle performance after posterior lumbar surgery. Spine 120:1023-1028

6. Rantanen J, Hurme M, Falck B et al (1993) The lumbar multifidus muscle five years after surgery for a lumbar intervertebral disc herniation. Spine 18:568-574

7. Sihvonen T, Herno A, Paljiarvi L et al (1993) Local denervation atrophy of paraspinal muscles in post operative failed back syndrome. Spine 18:575-581

8. Styf JR, Willen J (1998) The effects of external compression by three different retractors on pressure in the erector spine muscles during and after posterior lumbar spine surgery in humans. Spine 23:354-358

9. Foley KT, Lefkowitz MA (2002) Advances in minimally invasive spine surgery. Clin Neurosurg 49:499-517

10. Molinari RW, Bridwell SJ, Klepps SJ et al (1999) Minimum 5 year follow up of anterior column structural allografts in the thoracic and lumbar spine. Spine 24:967-972

11. Mannion R, Nowitzke A, Wood M (2010) Promoting fusion in minimally invasive lumbar interbody stabilisation with low dose BMP-2-but what is the cost? Spine J [E-pub prior to print]

12. Park P, Foley KT (2008) Minimally invasive transforaminal lumbar interbody fusion with reduction of spondylolisthesis: technique and outcomes after a minimum of 2 years' follow-up. Neurosurg Focus 25:E16

13. Mura PP, Costaglioli M, Piredda M, Caboni S, Casula S (2011) TLIF for symptomatic disc degeneration: a retrospective study of 100 patients. Eur Spine J 20(Suppl 1):S57-S60

14. Faundez AA, Schwender JD, Safriel Y, Gilbert TJ, Mehbod AA, Denis F, Transfeldt EE, Wroblewski JM (2009) Clinical and radiological outcome of anterior-posterior fusion versus transforaminal lumbar interbody fusion for symptomatic disc degeneration: a retrospective comparative study of 133 patients. Eur Spine J 18(2):203-211

15. Schwender JD, Holly LT, Rouben DP et al (2005) Minimally invasive transforaminal lumbar interbody fusion (TLIF): technical feasibility and initial results. J Spinal Disord Tech 18(suppl 1):S1-S6

16. Schizas C, Tzinieris N, Tsiridis E et al (2009) Minimally invasive versus open transforaminal lumbar interbody fusion: evaluating initial experience. Int Orthop 33:1683-1688

17. Peng CW, Yue WM, Poh SY et al (2009) Clinical and radiological outcomes of minimally invasive versus open transforaminal lumbar interbody fusion. Spine 34:1385-1389

18. Villavicencio AT, Burneikiene S, Roeca CM et al (2010) Minimally invasive versus open transforaminal lumbar interbody fusion. Surg Neurol Int 1:12

19. Shunwu F, Xing Z, Fengdong Z et al (2010) Minimally invasive transforaminal lumbar interbody fusion for the treatment of degenerative lumbar diseases. Spine 35:1615-1620

20. Wang J, Zhou Y, Zhang ZF, Li CQ, Zheng WJ, Liu J (2011) Minimally invasive or open transforaminal lumbar interbody fusion as revision surgery for patients previously treated by open discectomy and decompression of the lumbar spine. Eur Spine J 20(4):623-628 
21. Wang J, Zhou Y, Zheng Z et al (2010) Comparison of one-level minimally invasive and open transforaminal lumbar interbody fusion in degenerative and isthmic spondylolisthesis grades 1 and 2. Eur Spine J 19:1780-1784

22. Dhall SS, Wang MY, Mummaneni PV (2008) Clinical and radiographic comparison of mini-open transforaminal lumbar interbody fusion with open transforaminal lumbar interbody fusion in 42 patients with long-term follow-up. Neurosurg Spine 9:560-565
23. Isaacs RE, Podichetty VK, Santiago P et al (2005) Minimally invasive microendoscopy-assisted transforaminal interbody fusion with instrumentation. J Neurosurg Spine 3:98-105

24. Karikari IO, Isaacs RE (2010) Minimally invasive transforminal lumbar interbody fusion: a review of techniques and outcomes. Spine 35:S294-S301

25. Wu RH, Fraser JF, Hartl R (2010) Minimal access versus open transforaminal lumbar interbody fusion. Spine 35:2273-2281 